Post-print of the published book chapter:

Orozco-Jutorán, M. (2000) "Building a Measuring Instrument for the Acquisition of Translation Competence in Trainee Translators", in Schaeffner, C.; B. Adabs

(eds.) Developing Translation Competence, Amsterdam: John Benjamins, p. 199214.

\title{
BUILDING A MEASURING INSTRUMENT FOR THE ACQUISITION OF TRANSLATION COMPETENCE IN TRAINEE TRANSLATORS.
}

By Mariana Orozco

Departament de Traducció i d'Interpretació

Universitat Autònoma de Barcelona

\section{Introduction: the notion of Translation Competence}

In Spain, there are several Translation Faculties where students coming mainly from secondary schools can get a Degree in Translation after a four-year period of study. It is thus assumed that translation can be taught and that it is the task of translation teachers, who are in most cases translators themselves, to develop translation competence in trainee translators.

Although there seems to be agreement on this point, nobody has yet defined the process through which students acquire translation competence. In fact, although many authors talk of translation competence (Krings 1986:501,522; Wilss 1989:140,146; Nord 1991:150, 152, 155 and 1996:101; Riedemann 1996:117; Lörscher 1991:41 and 1992:426; Toury 1991:62 and 1995:251; Fraser 1996a:72 and 1996b:87), few authors define the specific skills that constitute this competence.

One of the few models that does define the specific skills is that proposed by PACTE $^{\mathrm{i}}$ (PACTE, 1999:2-6), where translation competence is defined as "the underlying system of knowledge and skills needed to be able to translate." This model,

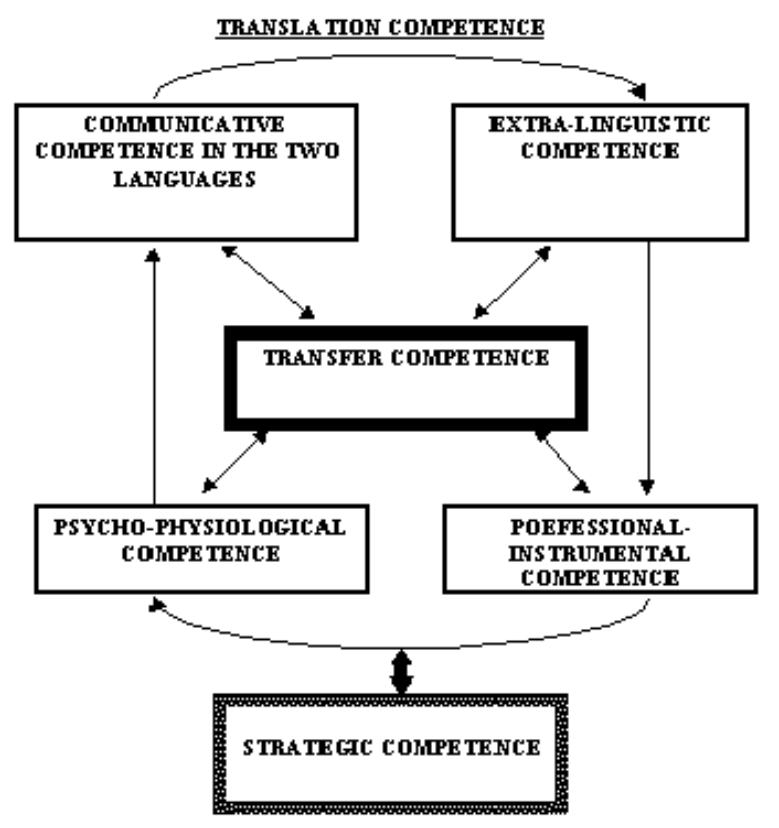


which is adopted here, describes translation competence through its components, as can be seen in figure 1 .

Fig. 1. The sub-components of Translation Competence (PACTE, 1999:3).

As figure 1 shows, transfer competence is the central competence of translation competence, and integrates all the others. It can be defined as "the ability to complete the transfer process from the ST to the TT, taking into account the translation's function and the characteristics of the receptor". Transfer competence is also divided into several subcomponents, which include (i) comprehension competence (the ability to analyse, synthesise and activate extra-linguistic knowledge so as to capture the sense of a text), (ii) the ability to "deverbalise" and to maintain the SL and the TL in separate compartments (i.e. to control interference), (iii) re-expression competence (textual organisation, creativity in the TL), (iv) competence in carrying out the translation project (the choice of the most adequate method).

There are four other components of translation competence surrounding transfer competence in figure 1: (i) communicative competence in two languages, which can be defined in general terms as "the system of underlying knowledge and skills necessary for linguistic communication". Following Canale (1983), a distinction is made between linguistic, discourse and socio-linguistic components. Of course, for translators, this competence should be separated into understanding in the SL and production in the TL; (ii) extra-linguistic competence is composed of general world knowledge and specialist knowledge that can be activated according to the needs of each translation situation. The sub-components may include explicit or implicit knowledge about translation, bicultural, encyclopaedic and subject knowledge; (iii) instrumental-professional competence is composed of knowledge and skills related both to the tools of the trade and the profession. The sub-components may be very diverse: knowledge and use of all kinds of documentation sources and new technologies, knowledge of the work market (translation briefs, etc.) and how to behave as a professional translator, especially in relation to professional ethics; (iv) psycho-physiological competence can be defined as "the ability to use all kinds of psychomotor, cognitive and attitudinal resources". The most important of these may be psychomotor skills for reading and writing; cognitive skills (e.g. memory, attention span, creativity and logical reasoning); psychological 
attitudes (e.g. intellectual curiosity, perseverance, rigour, a critical spirit, and selfconfidence).

Finally, the sixth component in translation competence, as shown in figure 1, is Strategic Competence, which includes all the individual procedures, conscious and unconscious, verbal and non-verbal, used to solve the problems found during the translation process. The problem-solving process can be described as a series of acts or recursive, complex acts that lead from an initial state to an objective. There are several stages in this process, the first of which is recognising there is a problem (Sternberg 1996). Examples of strategies are: distinguishing between main and secondary ideas, establishing conceptual relationships, searching for information, paraphrasing, back translating, translating out loud, establishing an order for documentation, etc.

The general aim of the research work presented in this paper is to shed new light on the whole process of acquisition of translation-specific skills and abilities, as a necessary step to finding an effective translation teaching methodology that will guide trainee translators in their learning process.

Given such an ambitious objective, attention is focused in this article on the first step towards achieving this goal: building measuring instruments for translation competence acquisition. The measuring instruments have been designed and piloted in order to work within the framework of a research project which will be described later on.

\section{Research methodology}

Until the mid-eighties much of the empirical research carried out in the field of Translation Studies used inductive, theoretical and observational methods. However, according to Toury (1995:1) “(...) empirical disciplines are devised to account, in a systematic and controlled way, for particular segments of the 'real world'. Consequently, no empirical science can make a claim for completeness and (relative) autonomy unless it has a proper descriptive branch. Describing, explaining and predicting phenomena pertaining to its object level is thus the main goal of such a discipline."

Some experimental research has been carried out over the past ten years, but most of the experimental studies lack some of the components deemed to be essential in the generally accepted definition of scientific methodology $y^{\mathrm{ii}}$. According to Nachmias and Nachmias (1982:22), "Scientific knowledge is knowledge provable by both reason 
and experience (observation). Logical validity and empirical verification are the criteria employed by scientists to evaluate claims for knowledge. These two criteria are translated into the research activities of scientists through the research process."

Figure 2 shows the seven main stages of the cycle through which the research process develops. It develops as follows: there is a problem, which leads to a hypothesis, which is the basis for a research design, which is followed by a measurement, data collection, data analysis, a conclusion and a possible generalisation, which in turn may pose another problem, which will lead to another hypothesis, and so on. At each stage, the process interacts with and is interdependent upon a theory (of translation, in this case), located at the centre of the research process.

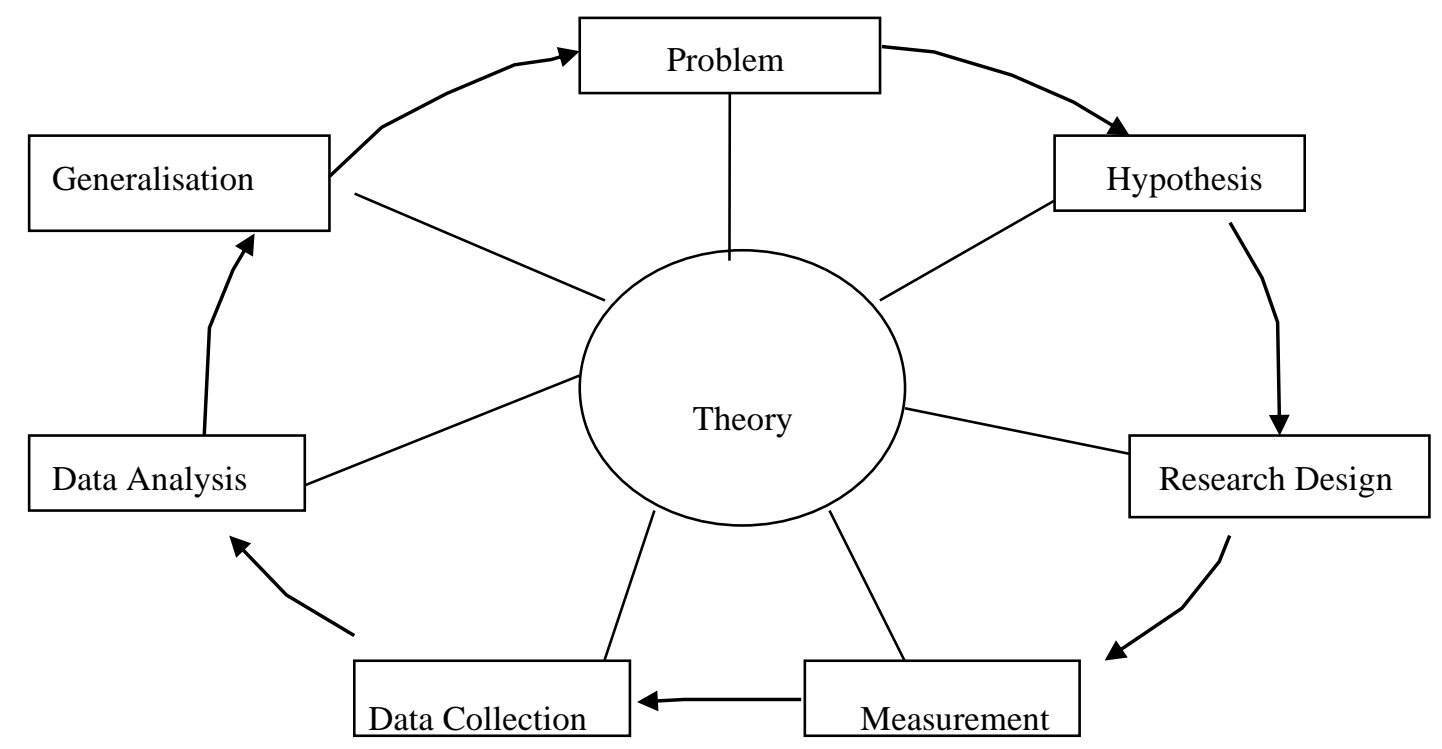

Fig 2. The Principal Stages of the Research Process (Nachmias and Nachmias 1982:23)

By following this cycle, replicability and the possibility of extrapolating results for their application to translation teaching is ensured. This methodology has been adopted for the research project proposed.

\section{Research design}

The main aim of the research project proposed is to measure translation competence acquisition in translation students at university, specifically at the first stage of their learning process (their first year of studies) and focusing only on translation from the foreign language (English, in this case) to their mother tongue. This is important because the measuring instruments which appear in appendix A have been 
designed for measuring this type of translation, and not translation to the foreign language.

These measuring instruments have undergone a series of pilot tests which have lasted three years (1996-1999), and during that time the instruments have been improved and tested, including reliability and validity tests.

In our opinion, the research design proposed could be used by any translation teacher who would like to investigate and learn a bit more about his/her students' process of translation competence acquisition. Figure 3 shows the main elements of the research design proposed. In fact, it is only a model and as such, could be modified in order to adapt to the interests of the researcher. For instance, one could decide to measure only one independent variable ("a") and thus only have three hypotheses ("a", "b" and "c") and no control group, etc.

\subsection{Main elements of the study}

1. Construct: Translation competence acquisition at its first stage.

\section{Independent variables:}

(a) period of exposure to translation training.

(b) exposure to a specific translation training methodology " $\mathrm{A}$ "

\section{Dependent variables:}

(a) students performance when faced with translation problems.

(b) students performance with regard to translation errors.

(c) translation notions.

4.Subjects: First year university students divided randomly into two groups, the experimental group and the control group.

\section{Measuring instruments:}
(a) to measure performance when faced with translation problems.
(b) to measure performance with regard to translation errors.
(c) to measure translation notions.

\section{Hypothesis:}
(a) subjects will detect and solve more problems as they progress with their translation training.
(b) subjects will make fewer errors as they progress with their translation training.
(c) subjects will acquire more translation notions as they progress with their translation training.
(d) subjects will detect and solve more problems if they follow the training methodology "A". 
(e) subjects will make fewer errors if they follow the training methodology " $\mathrm{A}$ ".

(f) subjects will acquire more translation notions if they follow the training methodology " $\mathrm{A}$ ".

Figure 3. Main elements of the study.

As Figure 3 shows, the construct to be studied in the proposed project is the process of acquisition of translation competence in its first stage, that is, during the first year of Translation Studies.

Subjects' progress in acquisition of translation competence is established on the basis of two measurements taken, one at the beginning of the trainee's studies (month 0 of tuition), and another one at the end of their first year (month 8 of tuition). These two measurements will henceforth be called M-1 and M-2, respectively.

The sample should be made up of the whole population of subjects to be studied, in this case, the first year university students which have chosen the language combination we are interested in (English-Spanish in this case), and the whole sample should be divided into two groups randomly, in order to form an experimental group and a control group. The control group is not necessary in order to test hypotheses (a), (b) and, (c), which deal with the independent variable a (time), but it is necessary to test hypotheses (d), (e) and (f), which deal with the teaching methodology used. The control group is the only way the researcher can assure that the difference between the results obtained in M-1 and M-2 are due to a specific teaching methodology. If the results in M-1 are the same for both groups (experimental and control), and the results in M-2 show a difference between both groups, then that difference can be attributed to the teaching method.

\subsection{Building the measuring instruments}

Three elements were selected as dependent variables, that is, as indicators of progress in the acquisition of translation competence: translation problems, translation errors and the students' general notions of translation. These three elements were then used to build three measuring instruments, one based upon each of these elements.

\section{Translation problems}

Following Nord (1991:151), a translation problem is conceived as "an objective problem which every translator (...) has to solve during a particular translation task". A translation problem may therefore appear at any stage of the translation process. It is observable (as will be explained when talking about the development of specific 
measuring instruments) and in solving a translation problem, the subject certainly shows his/her translation competence. These three qualities make translation problems reliable indicators of progress in acquiring translation competence.

\section{Translation errors}

The origin of a translation error, (Nord 1996:96-100) is usually a translation problem which has not been solved or has not been appropriately solved. Again, this element can be observed. It can take place at any stage of the translation process and it is also an indicator of a subject's translation competence. Translation errors therefore present the same three qualities as translation problems.

\section{Translation notions}

Finally, general knowledge of translation or notions of translation, determine the students' whole process of translation, since, depending on the ideas students have about translation, they will have a particular purpose for a particular translation task, and this will determine their solution of translation problems throughout the process of translation. Thus, a student who finds a problem in the source text can either ignore it or try to solve it. Should s/he decide to resolve it, the reason for that is that $\mathrm{s} / \mathrm{he}$ wants the target reader to understand or receive the target text in a certain way, and this is only possible if $s /$ he has a particular concept of translation in the back of his/her mind. If this concept did not exist, then there would not be an objective to achieve. In this case, errors (and/or unsolved problems) can be caused by this "lack of knowledge" of general translation concepts. Again, this element shares the same three qualities already mentioned: it is observable, it may influence the subject at any stage of the translation process and it is an indicator of the subjects' translation competence.

Progress made by each student in developing translation competence is determined by measuring performance in each of the three elements: problems, errors and translation notions. In the project proposed, measurements are taken at month 0 and month 8 of tuition. Level " 0 " is represented by the results obtained by each student at M-1, and, after the second measurement (M-2) after 8 months of tuition, a comparison between M-1 and M-2 should yield specific data about students' progress. Thus, the point of departure of each student varies at M-1, and the instruments measure the progress of individual students.

By using the three measuring instruments in this way, any teacher, for any language combination (changing the text, of course) and at any translation teaching centre will be able to study the progress made by his/her students. 


\section{Application and assessment of measuring instruments}

After a series of pilot studies, it was determined that the measurement of each element (problems, errors and notions of translation) in M-1 and M-2 should be carried out with a single questionnaire, like the one shown in appendix A, which contains the the three instruments and can be carried out by students in less than two hours. The version included in appendix $\mathrm{A}$ is a reduced one, where questions which yield qualitative data have been cut, in order to save space. However, anyone interested in the instruments can contact the author, who will supply the complete version.

\subsection{The translation notions instrument}

This instrument is a test which includes 12 items about the general notions of translation and of translation competence. It can be seen in the first two pages of appendix A. Although in the test in the appendix the questions are not in order, there are 6 items which correspond to the notion of translation (items 1, 5, 6, 7, 8 and 12) and 6 items which correspond tho the notion of translation competence (items 2, 3, 4, 9, 10 and 11). Therefore, there is a balance between the items asking about each of the two elements.

Each question can be awarded a maximum mark of 1 point mark. Six of the questions (7 to 12) are of the true or false type, allowing easy answering and assessment. In the true-false part of the test, a valid answer is awarded one point with an incorrect answer subtracting 0.5 points. In this way, the random element (students obtaining the correct answer only by guessing) will be eliminated.

Question 6 is different, as the subject is asked to underline; the correct answer is to underline all elements, and assessment is thus easy, as 0.1 is given to each of the elements underlined. No negative points are given in this question, since guessing is difficult with ten possiblities, and thus the random element is very small.

Finally, items 1, 2, 3 and 4, which are open questions, require a thoughtful assessment, which will depend on the notions taught by the teacher/researcher. However, as each of the questions can be awarded a maximum mark of one point, it is not very difficult to define a way to evaluate the anwer. For instance, in question 1, our proposal is that subjects should mention 5 elements in their definition: (i) languages (comprehension skills in foreign language and production skills in the target language); (ii) text as the unity to translate; (iii) extralinguistic parameters (encyclopaedic 
knowledge, cultural knowledge, specialist knowledge, etc.); (iv) a communication act (elements such as the client, the function or the reader, etc.); and (v) a mental process (a process which is not limited to languages but which includes mental abilities). For each of these five elements mentioned 0.1 or 0.2 points will be awarded depending on how elaborate the answers are. No negative points are given for these open questions, as there is no random element.

\subsection{The problems instrument}

As can be seen in the appendix (pages 3 and 4), students are asked to translate a text following a translation brief and then they have to answer one question which includes four sections.

In the text that students have to translate, four major problems have been identified, one corresponding to each of the following types: a linguistic problem, a transfer problem, an extralinguistic problem and a pragmatic problem.

Explaining the reasons for choosing these four types instead of other classifications, the specific text chosen and the specific problems found, would mean writing another article. Therefore, without going into details, we will only say that this text and these four problems were identified and agreed upon by several experts, and then several pilot studies were carried out with students in order to assure their validity.

When faced with the problem of how to apply this instrument, it was decided that importance was to be given to the three different stages involved in solving translation problems: a) detecting the problem, b) choosing the right strategies to solve the problem, and c) solving the problem. Depending upon the subjects' answers, 0,1 , or 2 points would be awarded. 0 points if they had not detected the problem, 1 point if they had detected the problem but had not solved it -or, in other words, had not applied the right strategies to solve it-, and 2 points if they had solved the problem appropriately.

The procedure involved in deciding whether a student is to be awarded 0,1 or 2 points is simplified by combining the translated text with the question which the students have to answer once they have completed their translation. A first assessment of the translated text accords 2 points for each translation problem solved. In those cases in which problems have not been solved in the translation, the assessor consults the question (see appendix A, page 4) in which the subject is asked if s/he found those segments in the text problematic where one of the four major problems mentioned before are located. If the subject answers "yes", then s/he is considered to have correctly 
identified the problem, and 1 point is awarded. If the answer is "no", then the problem has not been identified, and 0 points are awarded.

\subsection{The errors instrument}

The assessment of the errors instruments is just like a normal assessment carried out by any translation teacher in class. The text which has been translated by the subjects in the problems instrument is the one assessed. Therefore, this instrument does not require any extra effort or time on the part of the subject, it only requires correction on the part of the researcher.

The assessment system we propose is that designed by Hurtado (1995). This system starts off from 20 points, and consists of adding one point if there is a suitable solution, subtracting one point for a minor error and subtracting two points for a major error. However, any marking system can be used with this instrument, as long as the same system is used at M-1 and M-2, as the important point here is that the criteria used for assessment is maintained throughout the experiment.

\section{Conclusion}

At the end of one year's tuition, evaluating subjects' performance by using the three measuring instruments, the results for measurements M-1 and M-2 should make it possible to determine whether or not students have progressed in the acquisition of translation competence as well as to what degree they have progressed by comparing the progression in each of the series of three marks. The results may be useful for teachers of any language combination to measure the progress in their students during the first year of studies.

Similarly, measurements may be taken of two similar groups of subjects, one being taught using one teaching method and another using a second teaching method. If the results at the beginning of the year are the same in both groups and the results at the end of the year are different, then much of that difference can be attributed to the teaching method. This comparison of teaching methods can either be made by two teachers simultaneously or by the same teacher in two consecutive years. The results obtained may be useful in assessing the efficacy of different teaching methodologies.

Whatever way the measuring instruments are used, what is important is somehow to be able to measure the students' progress, in order to learn more about the way they learn to translate. By using the same instruments several times, one can know 
if translation problems are always related to translation errors, if the students learn first to detect problems and then to solve them, if their use of translation strategies (used to solve problems) progresses with their notion of translation. We may even find answers to many other related questions.

At present stage in our research, measuring instruments have been piloted with good results and have passed reliability and validity tests. Therefore, they are ready to be used in a research project like the one described in this article or in any other project based on the model proposed.

Finally, we would like to mention that both the research design and the instruments, as well as the reliability and validity tests constitute part of the author's doctoral thesis, directed by Amparo Hurtado Albir and Maria Carme Viladrich in the Departament de Traducció i d’Interpretació (Universitat Autònoma de Barcelona).

\footnotetext{
${ }^{\mathrm{i}}$ PACTE is a research group constituted by nine translation teachers from the Universitat Autònoma de Barcelona (A. Beeby, L. Berenguer, D. Ensinger, O. Fox, A. Hurtado Albir, N. Martínez Mélis, W. Neunzig, M. Orozco and M. Presas) who do empirical research focusing mainly on translation competence, the acquisition of translation competence and on teaching proposals to develop and evaluate translation competece.

ii In this respect, see Toury 1995:239-240.
} 


\section{BIBLIOGRAPHY}

CANALE, M. (1983) "From communicative competence to communicative language pedagogy", in J.C. RICHARDS; R.W. SCHMIDT (eds.)Language and Communication, London: Longman. p 2-28.

FRASER, Janet (1996a). "The Translator Investigated: learning from translation process analysis", in: The Translator, Vol.2, n 1. p 65-79.

FRASER, Janet (1996b). "Mapping the Process of Translation", in: Meta. Vol XLI, n 1, p 84-96.

HURTADO, Amparo (1995). "La didáctica de la traducción. Evolución y estado actual”, in: P. FERNÁNDEZ; J.M. BRAVO (eds.) Perspectivas de la traducción. Valladolid: Universidad de Valladolid. p. 49-74.

KRINGS, Hans P.(1986). Was in den Köpfen von Übersetzern vorgeht. Tübingen: Gunter Narr. [What Happens in the Minds of Translators]

LÖRSCHER, Wolfgang (1991). Translation Performance, Translation Process and Translation Strategies: A Psycholinguistic Investigation. Tübingen: Narr. 307 p.

LÖRSCHER, Wolfgang (1992). "Investigating the Translation Process", in Meta. Vol. XXXVII, n 3, p 426-39.

NACHMIAS, Chava; NACHMIAS, David (1982). Research Methods in the Social Sciences. 2nd ed. London: Edward Arnold (Hodder and Stoughton). 358 p.

NORD, Christiane (1991). Text Analysis in Translation. Amsterdam: Rodopi. 250 p.

NORD, Christiane (1996). "El error en la traducción: categorías y evaluación”, in: HURTADO, A. (ed.) La enseñanza de la traducción, col. Estudis sobre la traducció no 3 Castelló: Universitat Jaume I. p 91-107.

PACTE (1999) “Acquiring Translation Competence: Hypotheses and Methodological Problems of a Research Project", in: BEEBY, A; ENSINGER, D; PRESAS, M (eds.) Investigating Translation. Amsterdam: John Benjamins (forthcoming).

RIEDEMANN, Karin (1996). "Cognition and Translation Didactics", in: Meta. Vol. XLI, 1. p 114-117.

STERNBERG, R.J. (1996) Cognitive Psychology. Fort Worth, etc.: Harcourt Brace.

TOURY, Gideon (1991). "Experimentation in Translation Studies: achievements, prospects and some pitfalls", in: TIRKKONEN-CONDIT, S. (ed.). Empirical Research in Translation and Intercultural Studies: Selected papers of the TRANSIF Seminar, Savonlinna, 1988. Tübingen: Narr. p 45-66. 
TOURY, Gideon (1995) Descriptive Translation Studies and Beyond. Amsterdam/ Philadelphia: John Benjamins. 311 p.

WILSS, Wolfram (1989). “Towards a Multi-facet Concept of Translation Behavior", in: Meta. Vol. XXXIV, n 1, p 129-149. 
APPENDIX A

TRANSLATION NOTIONS INSTRUMENT

QUESTIONNAIRE ABOUT TRANSLATION

Name and Surnames:

Date of birth:

Please do the following exercises keeping to the order given here. You have two hours to complete the three exercises. Your answers will not be taken into account for the grades that you are given for this course, as the evaluators of this test will not be given your name. Therefore, please give spontaneous, honest answers to all the questions.

It is important that you answer the questions in order and that you do not go back to a question you have already answered. If you have any questions, put your hand up and we will try to help you.

\section{1- GENERAL NOTIONS ABOUT TRANSLATION QUESTIONNAIRE}

You will find three kinds of questions in this questionnaire:

A- Multiple-choice questions. Answer them by drawing a circle round the answer you consider to be the best, for example, a) is the right answer:

a)

b)

c)

B- True (T)/ False (F) questions. Answer them by drawing a circle round " $T$ " if you think the statement is true, or " $F$ " if you think the statement is false. In the following example the answer is true.

$\mathrm{F}$

C- Open questions. Answer them by writing your opinion on the dotted lines below each question.

You can begin as soon as you are ready:

1. What is translation for you? Define it in one sentence.

2. What should a good translator know? List the most important points.

3. Which instruments can help a translator to translate? List all the ones you know.

4. List all the different kinds of translations a professional translator may be asked to do.

5. When you are translating, what do you think is the basic unit you are translating?
a. the word
b. the sentence
c. something else: 
6. Underline the elements you think intervene in a translation.

client original author socio-cultural environment of the original text.

date of the original text socio-cultural environment of the translated text date of the translation. original reader. final reader.

function of the original text. function of the translation

7. The main problems encountered when translating are vocabulary problems.

$\mathrm{T} \quad \mathrm{F}$

8. Your translation of a sales contract for the British company, "WHL Inc.", will be different if you are translating it for a lawyer who wants to use it as proof in a trial, or for a Spanish subsidiary company, attached to "WHL Inc." that needs the translation to sign contracts with other Spanish companies.

T F

9. All translators should be able to translate as efficiently into the foreign language as into their mother tongue.

$\mathrm{T} \quad \mathrm{F}$

10. A good translator should be able to translate all types of texts with the same degree of efficiency.

T F

11. When a translator reads a text before translating it, the process is the same as for any other reader of the text.

$\mathrm{T} \quad \mathrm{F}$

12. A bilingual dictionary is the main instrument used to find an adequate equivalent in the target language.

T F 


\section{TRANSLATION PROBLEMS INSTRUMENT}

\section{2- TRANSLATION OF A TEXT FROM ENGLISH TO SPANISH (1 hour)}

Please translate the following test, taking into account the translation brief. You can use the white sheets of paper as rough paper, but your final translation should be written on page 5 of this folder.

Translation brief: A Spanish company has decided to start a business like "The Writers Bureau", with offices in Madrid, to teach writing in Spanish. You have been asked to translate the following advertisement (see page 4 of the folder), taken from the front page of The Guardian. Your translation will be published in El País exactly as you have delivered it to the Spanish newspaper.

ORIGINAL TEXT:

\section{Advertisement \\ Would you like to be a writer?}

by NICK DAWS

Freelance writing can be creative, fulfilling and a lot of fun, with excellent money to be made as well. What's more, anyone can become a writer. No special qualifications or experience are required. The market for writers is huge. In Britain alone there are around 1,000 daily, Sunday and weekly papers, and more than 8,000 magazines.

The Writers Bureau runs a comprehensive correspondance course covering every aspect of fiction and non-fiction writing.

The 140,000 word course is written by professional writers and has been acclaimed by experts.

\section{Why not be a writer?}

First-class home study course gets you a flying start. Earn while you learn . Expert tutors, personal guidance, help to sell your writing, and much more! It's ideal for beginners. Details free. No cost. No obligation. Send the coupon.

Name

Telephone.
Address

Postcode 


\section{3- QUESTIONNAIRE ABOUT THE TRANSLATED TEXT}

Answer the following questions about the text you have just translated. If you do not have enough space below each question, copy the number of the question at the end of the page, or on the back of the page and write the answer there. Use all the space you need. You can consult the original text (page 4 of this folder) and your translation (page 5 of this folder) to answer the questions.

1. Did you find the following segments of the text a problem to translate?

A: "flying" (line 21)

a. Yes

b. No.

B: "Sunday and weekly papers" (line 11)

a. Yes

b. No.

C: "It's ideal for beginners. Details free. No cost. No obligation. Send the coupon." (lines 22-23)

a. Yes

b. No.

D: "Britain" (line 10)

a. Yes

b. No. 